\title{
Interleukin-6/soluble interleukin-6 receptor complex reduces infarct size via inhibiting myocardial apoptosis
}

\author{
Kenichi Matsushita ${ }^{1}$, Shiro Iwanaga ${ }^{1}$, Takahiro Oda ${ }^{1}$, Kensuke Kimura ${ }^{1}$, Megumi Shimada ${ }^{1}$, \\ Makoto Sano ${ }^{2}$, Akihiro Umezawa ${ }^{2, *}$, Jun-ichi Hata ${ }^{2, \dagger}$ and Satoshi Ogawa ${ }^{1}$ \\ ${ }^{1}$ Cardiopulmonary Division, Department of Medicine, Keio University School of Medicine, Shinjuku-ku, \\ Tokyo, Japan and ${ }^{2}$ Department of Pathology, Keio University School of Medicine, Shinjuku-ku, Tokyo, Japan
}

\begin{abstract}
Apoptosis of cardiomyocytes plays an important role in reperfusion injury following myocardial infarction. Conversely, interleukin-6 (IL-6)—a potent cytokine-inhibits myeloma cell apoptosis by activating GP130 through the IL-6 receptor (IL-6R). We hypothesized that the IL-6/soluble IL-6R complex can inhibit myocardial apoptosis, and limit infarct size in reperfused acute myocardial infarction. Anesthetized rats were randomly divided into five groups: sham, coronary occlusion and reperfusion rats administered IL-6/soluble IL-6R complex, IL-6 alone, soluble IL-6R (sIL-6R) alone, or a control vehicle. Rats were subjected to $\mathbf{3 0}$ min occlusion of the left coronary artery followed by $3 \mathrm{~h}$ reperfusion. After reperfusion, the hearts were excised. For detection and quantification of apoptosis, gel electrophoresis of extracted genomic DNA and TUNEL method of paraffin sections were performed. The percentage of the infarct area was measured using tetrazolium chloride staining. The cardiomyocyte apoptosis analysis revealed that apoptosis in the reperfused myocardium was inhibited only in the complex group. Furthermore, the percentage of the infarct area out of the area at risk was remarkably reduced in the complex group $(23.8 \pm 1.8 \%)$, compared with that in the vehicle $(37.9 \pm 3.7 \%)$, the IL-6 (40.7 $\pm 1.0 \%)$, or the sIL-6R $(37.5 \pm 2.4 \%)$ groups $(P=0.0002)$. No significant differences were observed among the vehicle, IL-6, and sIL-6R groups. The IL-6/soluble IL-6 receptor complex inhibits cardiomyocyte apoptosis in reperfused acute myocardial infarction. It possibly reduces irreversible reperfusion injury.
\end{abstract}

Laboratory Investigation (2005) 85, 1210-1223. doi:10.1038/labinvest.3700322; published online 1 August 2005

Keywords: apoptosis; gp130; interleukin-6; myocardial infarction; reperfusion

Interleukin-6/soluble interleukin-6 receptor (IL-6/ sIL-6R) complex exhibits various functions in the central nervous system, the hematopoietic system, and other tissues. ${ }^{1-6}$ Classically, many soluble receptors are used to inhibit ligand signaling of the native receptor. ${ }^{7}$ However, soluble IL-6R acts as an agonist of IL-6 activity. The receptor for IL-6 is composed of two distinct membrane-bound glycoproteins, an $80 \mathrm{kDa}$ cognate receptor subunit (IL-6R) and a $130 \mathrm{kDa}$ signal-transducing element (gp130). ${ }^{8-}$ 11 The binding of IL-6 to the IL-6R induces the homodimerization of gp130. Homodimerisation of

Correspondence: Dr S Iwanaga, MD, PhD, Cardiopulmonary Division, Department of Medicine, Keio University School of Medicine, 35 Shinanomachi, Shijuku-ku, Tokyo 160-8582, Japan. E-mail: siwanaga@sc.itc.keio.ac.jp

*Present address: National Research Institute for Child Health and Development, Tokyo 157-8535, Japan.

"Present address: National Center for Child Health and Development, Tokyo 157-8535, Japan.

Received 6 January 2005; revised 18 May 2005; accepted 6 June 2005; published online 1 August 2005 the two gp130 molecules causes phosphorylation of gp130 and the transcription factors STAT1 and STAT3 by Janus-Kinases (JAK1, JAK2, TYK2), which are constitutively associated with gp $130 .{ }^{12}$ Neither IL-6 nor IL-6R alone binds or activates gp130. The heterodimeric complex IL-6/ IL-6R acts as the active cytokine. ${ }^{6}$ A soluble form of the IL-6R (sIL-6R) is still able to bind IL-6 and the complex of IL-6 and the sIL-6R activates target cells expressing gp130. In IL-6 signaling, the activation of STAT3 was shown to be linked with antiapoptotic signals through the induction of bcl-2. ${ }^{13}$ Furthermore, IL-6 was reported to inhibit apoptosis of malignant plasma cells, ${ }^{14}$ which express IL-6 receptors. ${ }^{15,16}$ In target cells expressing membrane-bound IL-6R, the function of IL-6 is further augmented by the addition of sIL-6R. ${ }^{17,18}$ In target cells expressing a small or no available number of membrane-bound IL-6R but expressing gp130, exogenously added IL-6 fail to exert its functions; however, coadministration of soluble IL-6R with IL-6 induces IL-6-mediated functions. ${ }^{1,5}$ 
Although gp130 is expressed on cardiomyocytes, ${ }^{9,19}$ whether cardiomyocytes express IL-6R is controversial. Saito et $a l^{9}$ reported that cardiomyocytes did not express IL-6R, while Youker et al showed that IL-6 activated IL-6 signal pathway in cardiomyocytes. ${ }^{20}$ Chandrasekar et $a l^{21}$ did not detect IL-6R mRNA in control myocardium, but found its upregulation in ischemic/reperfused myocardium. To examine whether IL-6 signaling inhibits apoptosis of cardiomyocyte as well as myeloma cells, a rat myocardial ischemia/reperfusion model, in which apoptosis of cardiomyocytes has previously been documented, ${ }^{22}$ was used in this investigation.

Clinically, the mainstay of treatment for acute myocardial infarction has strived to decrease the amount of infarcted myocardium. This has involved timely intervention by reperfusion of the occluded coronary artery; early reperfusion techniques include primary angioplasty and thrombolytic therapy. ${ }^{23}$ However, the apparent protective effect of timely reperfusion in acute myocardial infarction is accompanied by a paradoxical acceleration in residual cell death of the reperfused myocardium. These potential deleterious effects of reperfusion on the myocardium constitute the dilemma of reperfusion injury. ${ }^{24,25}$ The precise mechanism of reperfusion injury remains to be elucidated; however, myocardial apoptosis has been thought to contribute significantly to reperfusion injury. ${ }^{22,26,27}$ Optimizing the process of reperfusion to reduce these deleterious effects, perhaps by the administration of adjunctive therapies or by altering the myocardial environment, could further improve the outcome of clinical intervention. ${ }^{28,29}$

In the present study, we showed that IL-6/sIL-6R complex, but not IL-6 or sIL-6R alone, inhibited myocardial apoptosis in reperfused acute myocardial infarction. We further showed that IL-6/sIL-6R complex reduced infarct size in this model.

\section{Materials and methods}

\section{Experimental Protocols}

Human recombinant IL-6 was obtained from INTERGEN (New York, USA). Human sIL-6R was generously provided by Dr Tadamitsu Kishimoto of Osaka University. Human sIL-6R has been purified from human serum and urine. ${ }^{8,17,30}$ This soluble receptor binds IL-6 with an affinity similar to that of the cognate receptor $(0.5-2 \mathrm{nM})^{31,32}$ and prolongs its plasma half-life. ${ }^{8,33}$ The IL-6/sIL-6R complex is capable of activating cells via interaction with membrane-bound gp130. The molecular mass of IL-6/sIL-6R complex ( $\sim 60 \mathrm{kDa})$ is about three-fold higher than that of IL-6 ( $\sim 20 \mathrm{kDa})$. In this study, the IL-6/sIL-6R complex was made by incubating human recombinant IL-6 (3.3 $\mu \mathrm{g} / \mathrm{kg}$ body weight) with an excess amount of human sIL-6R $(33 \mu \mathrm{g} / \mathrm{kg}$ body weight) for $15 \mathrm{~min}$ at $37^{\circ} \mathrm{C}$ in vitro. For example,
$9.9 \mu \mathrm{l}$ of human recombinant IL-6 $(100 \mathrm{ng} / \mu \mathrm{l}$ in $\left.\mathrm{ddH}_{2} \mathrm{O}\right)$ and $19.8 \mu \mathrm{l}$ of human sIL-6R $(500 \mathrm{ng} / \mu \mathrm{l}$ in PBS) were mixed for a rat weighting $300 \mathrm{~g}$. Then we added normal saline to a final volume of $200 \mu \mathrm{l}$.

Male Wister rats weighing 270-325g were anesthetized with sodium pentobarbital $(50 \mathrm{mg} / \mathrm{kg}$, i.p.) prior to surgery. Rats were randomly divided into five major groups: sham-operated rats $(n=4)$, coronary occlusion and reperfusion rats administered IL-6/sIL-6R complex $(n=13)$, a control vehicle $(n=13)$, human recombinant IL-6 $(3.3 \mu \mathrm{g} / \mathrm{kg}$ body weight, $n=11)$, or human sIL-6R $(33 \mu \mathrm{g} / \mathrm{kg}$ body weight, $n=11$ ). The volume of each drug is adjusted to $0.2 \mathrm{ml}$ with a control vehicle, normal saline. The drugs were injected into the left ventricular cavity in vivo through the carotid cannula $15 \mathrm{~min}$ before coronary occlusion.

The animals were intubated and ventilated with a rodent respirator. A midline sternotomy was performed, and the heart was exposed. A reversible 4-0 silk slip knot was placed around the left coronary artery, approximately $5 \mathrm{~mm}$ distal from its origin, effectively occluding the vessel. Coronary occlusion was maintained for $30 \mathrm{~min}$, at which time the slip knot was released, initiating reperfusion. Shamoperated control rats underwent the same surgical procedure except that the suture passed under the left coronary artery was not tied. We injected all the rats included sham-operated rats with $2 \mathrm{mg} / \mathrm{kg}$ of lidocaine through carotid catheter just after the coronary occlusion to prevent sustained ventricular tachycardia. After $3 \mathrm{~h}$ reperfusion, the left coronary artery was reoccluded briefly, and $1 \mathrm{ml}$ phthalocyanine blue dye was injected into the left ventricular cavity in vivo and allowed to perfuse the nonischemic region of the heart, as previously reported. ${ }^{34}$ Then, the heart was excised and divided into three regions: nonischemic, border, and ischemic.

In the experiments using tissue sections, we identified the border region as being at the edge of the blue-dye-stained region. This border region included both perfused myocardium and ischemic myocardium, because of interdigitation of intramyocardial coronary arteries. Therefore, in the extraction of genomic DNA, we identified the border region as the tissue mass which included an equal amount of the blue-dye-stained and nonblue-dyestained region abutting the edge of the blue-dyestained area, and whose total weight was approximately $100 \mathrm{mg}$.

The study was approved by the Keio University School of Medicine Care of Experimental Animals Committee.

\section{Hemodynamic Evaluation}

The right carotid artery was cannulated with a $22 \mathrm{G}$ teflon catheter connected to a pressure transducer (Nihon Koden, Tokyo, Japan). By monitoring arterial blood pressure, the catheter was advanced into the 
left ventricular cavity for evaluation of left ventricular pressure and also for injection of the drugs.

\section{Infarct Sizing}

After reperfusion, the left coronary artery was reoccluded briefly, and $1 \mathrm{ml}$ phthalocyanine blue dye was injected into the left ventricular cavity in vivo and allowed to perfuse the nonischemic region of the heart. The entire heart was excised and sliced transversely into sections approximately $2 \mathrm{~mm}$ in thickness. The slices were photographed and then incubated in a $1 \%$ solution of tetrazolium chloride (TTC) for $10 \mathrm{~min}$ at $37^{\circ} \mathrm{C}$ to stain the viable myocardium brick red. The samples were fixed in $10 \%$ buffered formalin for $24 \mathrm{~h}$ and then photographed. The area at risk (regions not stained with phthalocyanine blue dye) and the infarcted area (regions not stained with TTC) were outlined on each photograph and measured using an image analyzer. Infarct size was expressed as a percentage of the infarcted area divided by the area at risk.

\section{Agarose Gel Electrophoresis of DNA}

Extracted genomic DNA was dissolved in TE buffer (10 mM Tris- $\mathrm{HCl}$ and $1 \mathrm{mM}$ EDTA, $\mathrm{pH} 8.0$ ) at $50^{\circ} \mathrm{C}$ overnight. The DNA solution was treated with RNase $(100 \mu \mathrm{g} / \mathrm{ml})$ for $1 \mathrm{~h}$ at $37^{\circ} \mathrm{C}$.

In all, $12 \mu \mathrm{g}$ of DNA was electrophoresed in $2 \%$ agarose gel in TAE buffer $(40 \mathrm{mM}$ Tris- $\mathrm{HCl}, 30 \mathrm{mM}$ acetic acid, and $2 \mathrm{mM}$ EDTA, pH 8.0) for $5 \mathrm{~h}$ at $50 \mathrm{~V}$. After electrophoresis, the gel was stained in vistra green solution (Amersham, Buckinghamshire, UK), and the DNA was visualized using the Fluor imager (Molecular Dynamics Inc., CA, USA) as previously reported. ${ }^{34}$ To confirm DNA ladder formation, the linear distribution of signal intensity for each lane was analyzed using the Image QuaNT software (Molecular Dynamics Inc.).

\section{TdT-Mediated dUTP-Biotin Nick End Labeling (TUNEL)}

Fragmented DNA was detected in myocardial sections using a modified end-labeling technique as previously reported. ${ }^{34}$ Paraffin-embedded myocardial sections were mounted on glass slides. Nonischemic and ischemic area orientation was confirmed by phthalocyanine blue dye. The slides were incubated with $5 \mu \mathrm{g} / \mathrm{ml}$ of proteinase $\mathrm{K}$ for $15 \mathrm{~min}$ at room temperature (RT), and then the endogenous peroxidase was inactivated by immersing the sections in $2 \% \mathrm{H}_{2} \mathrm{O}_{2}$. Deoxynucleotidyl transferase $(0.3 \mathrm{U} / \mathrm{ml})$ and biotinylated dUTP in TdT buffer $(30 \mathrm{mM}$ Tris-HCl, pH 7.2, $140 \mathrm{mM}$ sodium cacodylate, $1 \mathrm{mM}$ cobalt chloride) were added to cover the sections and the sections were incubated in a humid chamber at $37^{\circ} \mathrm{C}$ for $60 \mathrm{~min}$. After washing, the sections were covered with streptavidin peroxidase for $15 \mathrm{~min}$ at RT, and then stained with 3,3'-diaminobenzidine tetrahydrochloride. The sections were counterstained with methyl-green. Positive control samples were prepared by incubating sections with DNase I prior to treatment with terminal transferase. Negative controls consisted of specimens in which deoxynucleotidyl transferase was omitted.

To determine the ratio of TUNEL-positive myocytes, the number of TUNEL-positive cardiomyocyte nuclei was divided by the total number of cardiomyocyte nuclei. Six representative microscopic fields were analyzed for each region.

\section{Electron Microscope}

The hearts were subjected to perfusion-fixation with Karnovsky's fixative before excision. Tissue samples from ischemic, border, and nonischemic regions were immersed in Karnovsky's fixative. Thin sections were mounted on grids; scanned and photographed.

\section{Blood Analysis}

The right femoral artery was cannulated with a $24 \mathrm{G}$ teflon catheter to obtain blood samples. In all, $4 \mathrm{ml}$ of arterial blood was drawn from the femoral artery immediately after $3 \mathrm{~h}$ reperfusion but before dye injection. In addition to blood counts, the plasma was separated and C-reactive protein (CRP) was quantified by Latex Agglutination-Turbidimetric Immunoassay, using LZ TEST 'EIKEN' CRP kit according to the manufacture's instruction (Eiken Chemical Co., Ltd., Tokyo, Japan).

\section{Immunoprecipitation and Western Blot Analysis}

Polyclonal antibodies to gp130 and monoclonal antibody to phosphotyrosine were obtained from Upstate Biotechnology (Lake Placid, NY, USA). Sham-operated rats were used for this experiment. Without the occlusion of the left coronary artery, LV tissues were harvested at $0,5,15,30$, and $60 \mathrm{~min}$ after the injection of IL-6/sIL-6R complex into LV cavity through the carotid catheter. LV tissues were homogenized in lysis buffer $(150 \mathrm{mM} \mathrm{NaCl}, 0.02 \%$ sodium azide, $0.1 \%$ SDS, $100 \mu \mathrm{g} / \mathrm{ml}$ PMSF, $1 \mu \mathrm{g} / \mathrm{ml}$ aprotinin, $1 \%$ NP-40, $0.5 \%$ sodium deoxycholate, $50 \mathrm{mM} \mathrm{NaF}, 25 \mathrm{mM} \beta$-glycerophospate, and $1 \mathrm{mM}$ $\mathrm{Na}_{3} \mathrm{VO}_{4}$ in $50 \mathrm{mM}$ Tris-HCl, $\mathrm{pH}$ 8.0) and the $5 \mathrm{mg}$ of lysates were precleared by incubation with protein $\mathrm{G}$ sepharose (Amersham Pharmacia Biotech, NJ, USA) for $1 \mathrm{~h}$ at $4^{\circ} \mathrm{C}$. After centrifugation, the lysates were incubated with the monoclonal antibody to phosphotyrosine overnight at $4^{\circ} \mathrm{C}$. Immunocomplexes were collected by incubating with $40 \mu \mathrm{l}$ of protein $\mathrm{G}$ sepharose for $2 \mathrm{~h}$. Immunoprecipitates were washed five times with TBS-T $(0.1 \%$ tween-20 and $137 \mathrm{mM} \mathrm{NaCl}$ in $20 \mathrm{mM}$ Tris-HCl, pH 7.6). The precipitated proteins were dissolved in sample buffer (10\% glycerol, $2.3 \%$ SDS and $5 \% \beta$-mercap- 
toethanol in $62.5 \mathrm{mM}$ Tris-HCl, $\mathrm{pH}$ 6.8) and heated at $95^{\circ} \mathrm{C}$ for $5 \mathrm{~min}$. Proteins were separated by $7.5 \%$ sodium dodecyl sulfate-polyacrylamide gel electrophoresis (SDS-PAGE). Protein fractions were then electrophoretically transferred onto a polyvinylidene difluoride (PVDF) membrane. The membrane was blocked with $5 \%$ nonfat-dried milk in TBS-T. Then the membrane was incubated with rabbit polyclonal antibody to gp130 for $1 \mathrm{~h}$ at RT. The primary antibody was diluted 1:100 in blocking solution. After washing in TBS-T, it was incubated with horseradish peroxidase-conjugated swine antirabbit immunoglobulin diluted to 1:1000 in blocking solution. The antigen antibody-peroxidase complex was visualized using the ECL chemiluminescence detection kit (Amersham International, Buckinghamshire, UK).

\section{Statistical Analysis}

All values are expressed as the mean \pm s.e.m. Statistical significance was determined using an ANOVA followed by the Bonferroni test. $P$-values less than 0.05 were considered statistically significant.

\section{Results}

\section{Assessment of Infarct Size}

Infarct size, or the percent infarct area, was evaluated as a percentage of infarct area to area at risk. Phthalocyanine blue dye and TTC staining were performed to estimate area at risk and infarct area, respectively (Figure 1a). The average area at risk was $45.9 \pm 2.9 \%$ in the vehicle-treated group, $53.3 \pm 3.1 \%$ in the IL-6/sIL-6R complex-treated group, $49.3 \pm 3.8 \%$ in the IL-6-treated group, and $51.4 \pm 2.5 \%$ in the sIL-6R-treated group, with no significant differences among the four groups (ANOVA). However, there were significant differences $(P=0.0002$ by ANOVA) in the percentage of the infarct area relative to the area at risk (percent infarct area) among the IL-6/sIL-6R complextreated $(23.8 \pm 1.8 \%)$, vehicle-treated $(37.9 \pm 3.7 \%)$, IL-6-treated $(40.7 \pm 1.0 \%)$, and sIL-6R-treated $(37.5 \pm 2.4 \%)$ groups (Figure $1 \mathrm{~b})$. The results of the Bonferroni test showed that only the IL-6/sIL-6R complex-treated group showed a significantly smaller $(P=0.0004)$ percent infarct area than the vehicletreated group (three comparisons). The IL-6-treated and sIL-6R-treated groups showed no significant differences from the vehicle-treated group.

\section{Heart Rate and Left Ventricular Pressure}

ANOVA revealed no significant differences in the heart rate (HR), left ventricular systolic pressure, or left ventricular end diastolic pressure measured before coronary occlusion, after coronary occlusion, or after reperfusion among the vehicle-treated, IL-6/ sIL-6R complex-treated, IL-6-treated, and sIL-6Rtreated groups (Table 1). The reduction in the infarct size was not considered to be related to the HR or blood pressure, but to an antiapoptotic effect.

\section{Cardiac Arrhythmias}

Almost all arrhythmias occurred between 5 and $15 \mathrm{~min}$ after coronary occlusion. Some rats showed isolated premature ventricular contraction (PVC) just after the reperfusion but those arrhythmias were not severe. In this study, we injected all the rats included sham-operated rats with $2 \mathrm{mg} / \mathrm{kg}$ of lidocaine through carotid catheter just after the coronary occlusion to prevent sustained ventricular tachycardia (VT). Even after the injection of lidocaine, some rats still exhibited PVC or nonsustained VT between 5 and $15 \mathrm{~min}$ after coronary occlusion. However, they were transient and recovered without additional drugs. Although we did not observe the difference in arrhythmias among the vehicle-treated, IL-6/sIL-6R complex-treated, IL-6-treated, and sIL6R-treated groups, we cannot exclude the possibility that lidocaine masked the difference in arrhythmias.

\section{Blood Analysis}

There were no significant differences in the white blood cell count or serum CRP level among the vehicle-treated, IL-6/sIL-6R complex-treated, IL-6treated, and sIL-6R-treated groups (Table 2).

\section{Agarose Gel Electrophoresis}

Genomic DNA obtained from the ischemic and the border regions of the vehicle group showed typical DNA laddering with reduced high molecular weight genomic DNA. However, DNA from any region of the IL-6/sIL-6R complex group as well as from the nonischemic region of the vehicle group did not exhibit DNA fragmentation. DNA from nonischemic regions as well as specimens taken from the border region of the IL-6/sIL-6R complex group exhibited preservation of high molecular weight genomic DNA bands (Figure 2). Similar to the vehicle group, DNA from the ischemic and the border regions of the IL-6 or sIL-6R group showed typical DNA laddering with reduced high molecular weight genomic DNA (Figure 3). Thus, specimens taken from only the IL-6/sIL-6R complex group exhibited inhibition of cardiomyocyte apoptosis following reperfusion.

\section{In Situ DNA Fragmentation by TUNEL Staining}

To visualize apoptosis in situ, the TUNEL method was employed to detect apoptotic nuclei in myocardial cells. In the nonischemic regions, positively stained nuclei were rarely detected in the rat hearts. 

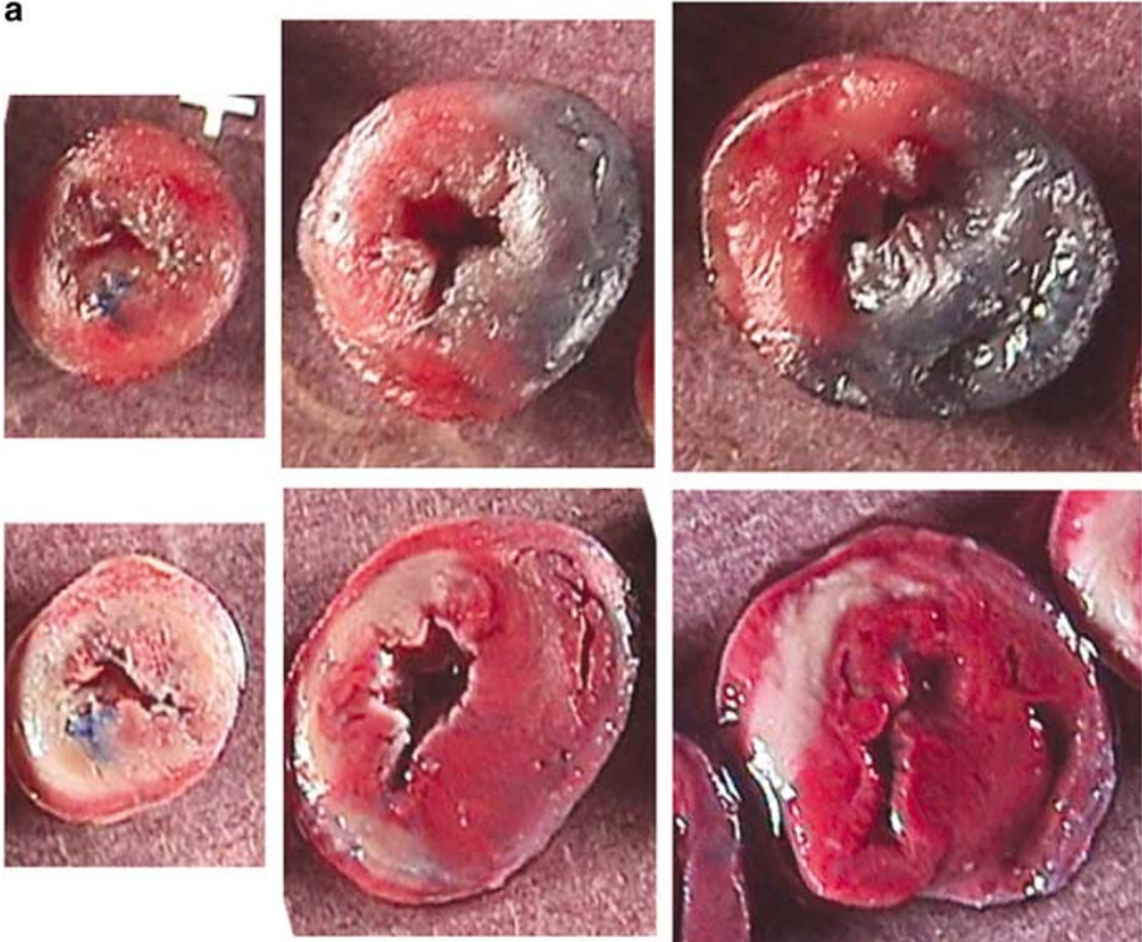

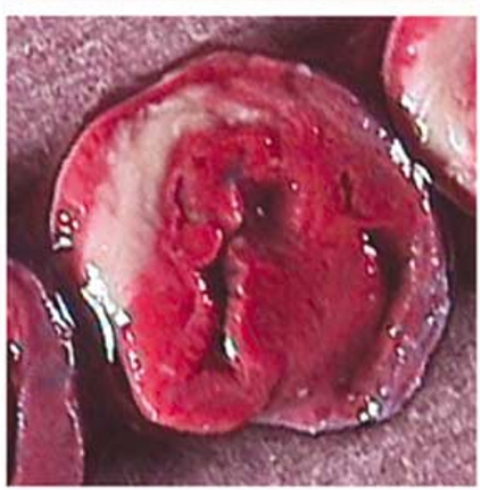

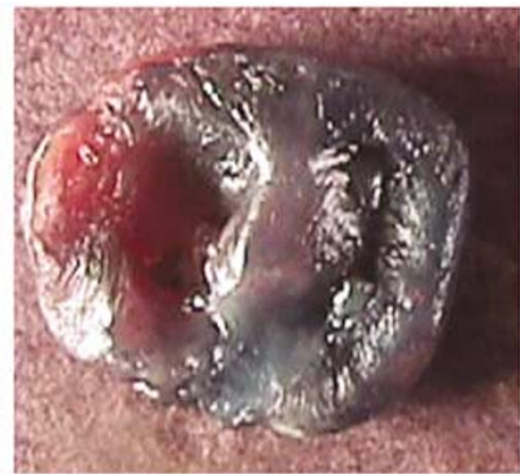

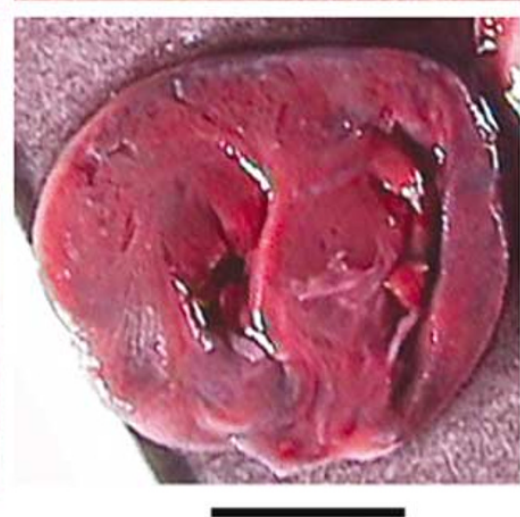

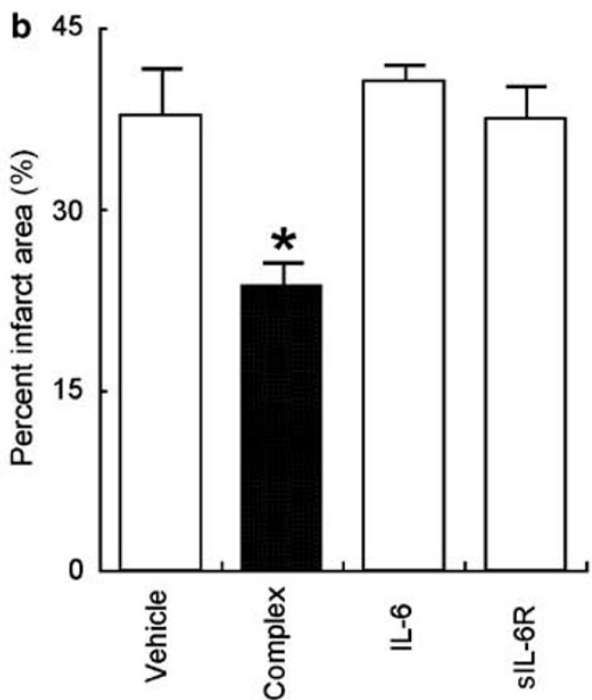

Figure 1 Assessment of infarct size. (a) Photos of rat hearts showing phthalocyanine blue dye and tetrazolium chloride (TTC) staining. The heart was sliced transversely into sections approximately $2 \mathrm{~mm}$ in thickness. The area at risk was defined as regions not stained with phthalocyanine blue dye, shown in the upper panels, and the infarct area was defined as regions not stained with TTC (white area), shown in the lower panels. Each pair of upper and lower panels represents the same slice. The infarct size, or the percent infarct area, was evaluated as a percentage of the infarct area relative to the area at risk. Bar represents $5 \mathrm{~mm}$. (b) Bar graph representing the percentage of the infarct area relative to the area at risk in rat hearts subjected to $30 \mathrm{~min}$ ischemia and $3 \mathrm{~h}$ reperfusion after the administration of the control vehicle, IL-6, sIL-6R, or the IL-6/soluble IL-6R complex. The drugs were injected in vivo into the LV cavity through a carotid cannula $15 \mathrm{~min}$ before coronary occlusion. The percentage of infarct area relative to the area at risk was significantly smaller in the IL-6/ sIL-6R complex-treated group $(23.8 \pm 1.8 \%, n=7)$ than in the vehicle-treated $(37.9 \pm 3.7 \%, n=7)$, IL-6-treated (40.7 $\pm 1.0 \%, n=7)$, and sIL-6R-treated $(37.5 \pm 2.4 \%, n=7)$ groups. ${ }^{*} P<0.05$ vs vehicle-, IL-6-, and sIL-6R-treated groups. The error bar represents the s.e.m.

In the ischemic or border regions of the vehicle hearts, numerous TUNEL-positive nuclei were observed. However, in the ischemic and border regions of the IL-6/sIL-6R complex-treated hearts, only scattered positive nuclei were observed and there were considerably less positive nuclei compared with the vehicle-treated hearts (Figure 4). Similar to the vehicle hearts, numerous TUNEL-positive nuclei were observed in the ischemic or border regions of the IL-6-treated or sIL-6R-treated hearts (Figure 5). 
Table 1 Heart rate and left ventricular pressure

\begin{tabular}{|c|c|c|c|c|}
\hline & Vehicle & Complex & $I L-6$ & $s I L-6 R$ \\
\hline \multicolumn{5}{|c|}{ Heart rate (bpm) } \\
\hline Baseline & $395 \pm 20$ & $398 \pm 17$ & $361 \pm 8$ & $335 \pm 25$ \\
\hline occ 30 & $312 \pm 19$ & $330 \pm 11$ & $310 \pm 13$ & $291 \pm 24$ \\
\hline rep 30 & $310 \pm 22$ & $345 \pm 17$ & $325 \pm 18$ & $313 \pm 28$ \\
\hline rep 180 & $288 \pm 18$ & $345 \pm 12$ & $294 \pm 12$ & $289 \pm 18$ \\
\hline \multicolumn{5}{|c|}{ LVSP (mmHg) } \\
\hline Baseline & $107 \pm 6$ & $109 \pm 6$ & $126 \pm 4$ & $116 \pm 3$ \\
\hline occ 30 & $94 \pm 3$ & $104 \pm 4$ & $99 \pm 4$ & $89 \pm 8$ \\
\hline rep 30 & $96 \pm 5$ & $115 \pm 3$ & $104 \pm 5$ & $105 \pm 8$ \\
\hline rep 180 & $113 \pm 4$ & $125 \pm 5$ & $107 \pm 5$ & $106 \pm 7$ \\
\hline \multicolumn{5}{|c|}{ LVEDP (mmHg) } \\
\hline Baseline & $6.7 \pm 1.1$ & $5.9 \pm 1.1$ & $4.3 \pm 0.7$ & $6.4 \pm 0$ \\
\hline occ 30 & $5.6 \pm 0.7$ & $7.6 \pm 0.6$ & $8.4 \pm 1.0$ & $9.6 \pm 1$ \\
\hline rep 30 & $5.6 \pm 1.5$ & $8.6 \pm 0.7$ & $10.2 \pm 1.1$ & $7.4 \pm 1.1$ \\
\hline rep 180 & $5.9 \pm 0.6$ & $7.9 \pm 0.8$ & $5.4 \pm 0.2$ & $6.6 \pm 0.6$ \\
\hline
\end{tabular}

Complex =IL-6/sIL-6R complex; IL-6 = interleukin-6; LVEDP = left ventricular end diastolic pressure; $L V S P=$ left ventricular systolic pressure; occ $=$ occlusion; rep $=$ reperfusion; sIL-6R $=$ soluble interleukin-6 receptor.

Table 2 Blood analysis

\begin{tabular}{|c|c|c|c|c|}
\hline & Vehicle & Complex & $I L-6$ & slL-6R \\
\hline WBC $(/ \mu \mathrm{l})$ & $8600 \pm 1120$ & $7644 \pm 566$ & $6560 \pm 733$ & $6250 \pm 517$ \\
\hline $\mathrm{CRP}(\mathrm{mg} / \mathrm{dl})$ & $0.1 \pm 0.02$ & $0.1 \pm 0.02$ & $0.1 \pm 0.02$ & $0.1 \pm 0.02$ \\
\hline
\end{tabular}

Complex = IL-6/sIL-6R complex; CRP = C-reactive protein; IL-6 = interleukin-6; sIL-6R = soluble interleukin-6 receptor; $\mathrm{WBC}=$ white blood cell count.

Quantitatively, the ratio of TUNEL-positive myocytes in the ischemic (I) and border (B) regions was significantly smaller in the IL-6/sIL-6R complextreated group (I: $4.8 \pm 0.6 \%$, B: $3.9 \pm 0.7 \%$ ) than that in the vehicle-treated (I: $14.1 \pm 0.7 \%, B: 13.9 \pm$ $0.9 \%$ ), IL-6-treated (I: $13.1 \pm 0.7 \%$, B: $13.2 \pm 0.8 \%$ ), and sIL-6R-treated (I: $14.9 \pm 1.0 \%, B: 12.9 \pm 1.1 \%$ ) groups $(P<0.0001$ by ANOVA, $P<0.0001$ by Bonferroni test when comparing with the vehicle group in the same region, three comparisons in each region) (Figure 6). No significant differences were observed among the vehicle-treated, IL-6-treated, and sIL-6R-treated groups.

\section{Electron Microscope Findings}

To confirm cardiomyocyte apoptosis, we analyzed the vehicle-treated border and ischemic tissue sections by electron microscope. The ultrastructural features of apoptotic cells are known to be shrunk cells displaying segregation of chromatin into discrete clumps abutting the nuclear membrane, whereas cytoplasmic organelles most often kept a normal appearance. ${ }^{35}$ In the vehicle-treated border and ischemic sections, apoptotic myocytes pre- sented with complete nuclear chromatin condensation along the nuclear membrane (Figure 7). Consistent with previous studies on myocardial ischemia/reperfusion, ${ }^{26,27}$ we were not able to detect definite apoptotic bodies of cardiomyocyte origin in these sections.

\section{Activation of gp130 by IL-6/sIL-6 Receptor Complex}

To confirm the gp130 pathway is activated by the injection of IL-6/sIL-6R complex, we examined the tyrosine phosphorylation of gp130 in rat hearts. As shown in Figure 8, basal level of tyrosine phosphorylation of gp130 was very little but significant tyrosine phosphorylation of gp130 was observed in rat hearts after the infection of IL-6/sIL-6R complex. Intense phosphorylation of gp130 was observed between 5 and $15 \mathrm{~min}$ after injection. These results indicate that the IL-6/sIL-6R complex activates gp130 pathway.

\section{Assessment of Left Ventricular Function by $L V \mathrm{~d} P / \mathrm{d} t$}

Having demonstrated that our IL-6/soluble IL-6R complex reduces infarct size through inhibiting myocardial apoptosis, we compared LV function using $\mathrm{LV} \mathrm{d} P / \mathrm{d} t$ between vehicle-treated rats and IL6/sIL-6R complex treated rats. Since $\mathrm{LV} \mathrm{d} P / \mathrm{d} t$ is very sensitive to inotrophic changes, it is considered to be a good marker which reflects LV function. ${ }^{36-38}$ As shown in Table 3 , trends towards higher positive $\mathrm{d} P / \mathrm{d} t$ and negative $\mathrm{d} P / \mathrm{d} t$ were observed at $30 \mathrm{~min}$ after occlusion and at $30 \mathrm{~min}$ after reperfusion in IL-6/sIL-6 complex group; however, these differences did not reach statistical significance.

\section{Discussion}

In this study, we have shown that administration of IL-6/sIL-6R complex inhibits apoptosis in the reperfused myocardium. Furthermore, the above complex was also able to reduce infarct size. IL-6/sIL-6R complex has been reported to have various functions in the central nervous system, the hematopoietic system, and other tissues; ${ }^{1-6}$ however, the effect of the complex in myocardial infarction has not been directly assessed so far. This is the first report of the possible therapeutic effects of IL-6/sIL6R complex in reperfused myocardial infarction; our results suggest the possible use of this complex in the clinical treatment of reperfused myocardial infarction as well as other cardiac diseases involving apoptosis such as myocarditis and heart failure. ${ }^{39,40}$

IL-6/sIL-6R complex induces the homodimerization of gp130. Homodimerization of the two gp130 molecules causes phosphorylation of gp130 and the transcription factors STAT1 and STAT3 by Janus-Kinases (JAK1, JAK2, TYK2) and then acti- 


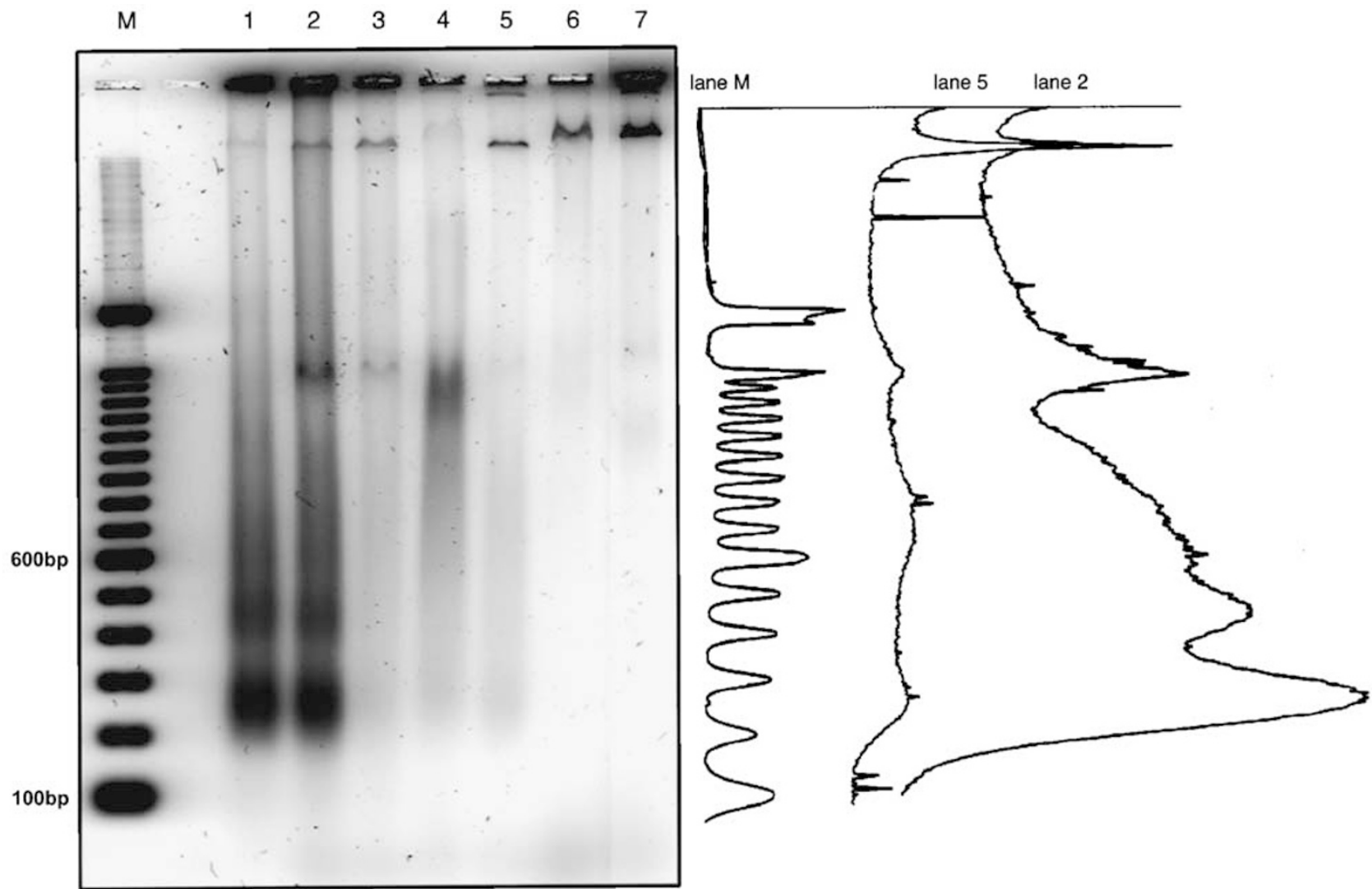

Figure 2 DNA ladder formation in rat heart administered either a control vehicle or IL-6/sIL-6R complex. Genomic DNA was extracted from rat myocardium and electrophoresed in 2\% agarose gel. Lanes 1-3 represent genomic DNA extracted from a heart exposed to 30 min ischemia and $3 \mathrm{~h}$ reperfusion and administered a control vehicle. Lanes 4-6 represent genomic DNA from a heart exposed to 30 min ischemia and $3 \mathrm{~h}$ reperfusion and administered the IL-6/sIL-6R complex (lanes 1 and 4: ischemic myocardium; lanes 2 and 5: border region myocardium; lanes 3 and 6: nonischemic myocardium). Genomic DNA from the ischemic and border regions (lanes 1 and 2) exhibited typical DNA laddering in the 200-600 bp range; however, genomic DNA from the nonischemic region (lane 3) exhibited preservation of high molecular weight DNA and did not exhibit DNA ladder formation typical of DNA fragmentation. In the IL-6/sIL-6R complex treated rat heart, the ischemic myocardium exhibited a smear pattern typical of degradated genomic DNA and did not exhibit DNA ladder formation. Genomic DNA from the border and nonischemic regions did not exhibit DNA ladder formation but did exhibit preservation of high molecular weight DNA. Lane 7 represented genomic DNA from a sham-operated heart and exhibited only the intact high molecular weight DNA band. M represents a $100 \mathrm{bp}$ DNA ladder marker. The graph on the right represents the linear distribution of signal intensity of the agarose gel DNA electrophoresis for lanes M, 5, and 2 (M: marker lane; 5 and 2: lanes representing DNA from the border regions of the IL-6/sIL-6R complex treated and control vehicle-administered hearts, respectively). This distribution pattern confirms that typical DNA laddering can be detected in lane 2 but not in lane 5. DNA from individual hearts were used. The experiment shown is representative of three experiments.

vates cellular signal processes. ${ }^{6,12,41-44}$ Our study indicated that administration of IL-6/sIL-6R complex, but not of IL-6 or sIL-6R alone, inhibited cardiomyocyte apoptosis in reperfused acute myocardial infarction. In this relation, it is of interest that coadministration of IL-6 and sIL-6R, but not IL6 or sIL-6R alone attenuated motor dysfunction and neuropathological changes in wobbler mouse motor neuron disease. ${ }^{45}$ Transgenic mice overexpressing both IL-6 and IL-6R present with hypertrophy of ventricular myocardium with advancing age; the myocardium in these animals has been shown to express gp130. ${ }^{46}$ However, transgenic mice overexpressing IL-6 or IL-6R alone did not present with detectable myocardial abnormalities. The present study also showed that administration of IL-6 or sIL$6 \mathrm{R}$ alone had no effects on cardiomyocytes. In IL-6 signaling, the activation of STAT3 was shown to be linked with antiapoptotic signals through the induction of bcl-2. ${ }^{13}$ Possible mechanism in our results is that exogenous IL-6/sIL-6R complex acts directly on cardiomyocytes by activating membraneanchored gp130 and inhibits cardiomyocyte apoptosis. Another possibility is that the above complex may act on other cell types (eg, leukocytes) and reduce reperfusion injury through altering the myocardial environment. Since we showed that IL6/sIL-6R complex induced tyrosine phosphorylation of gp130 within $5 \mathrm{~min}$, we speculate the former mechanism is a more reasonable explanation for our results. Other studies also showed that IL-6/sIL-6R complex as well as ciliary neurotrophic factor and leukemia inhibitory factor-members of the IL-6 family-reached to the cell surface of target organs 


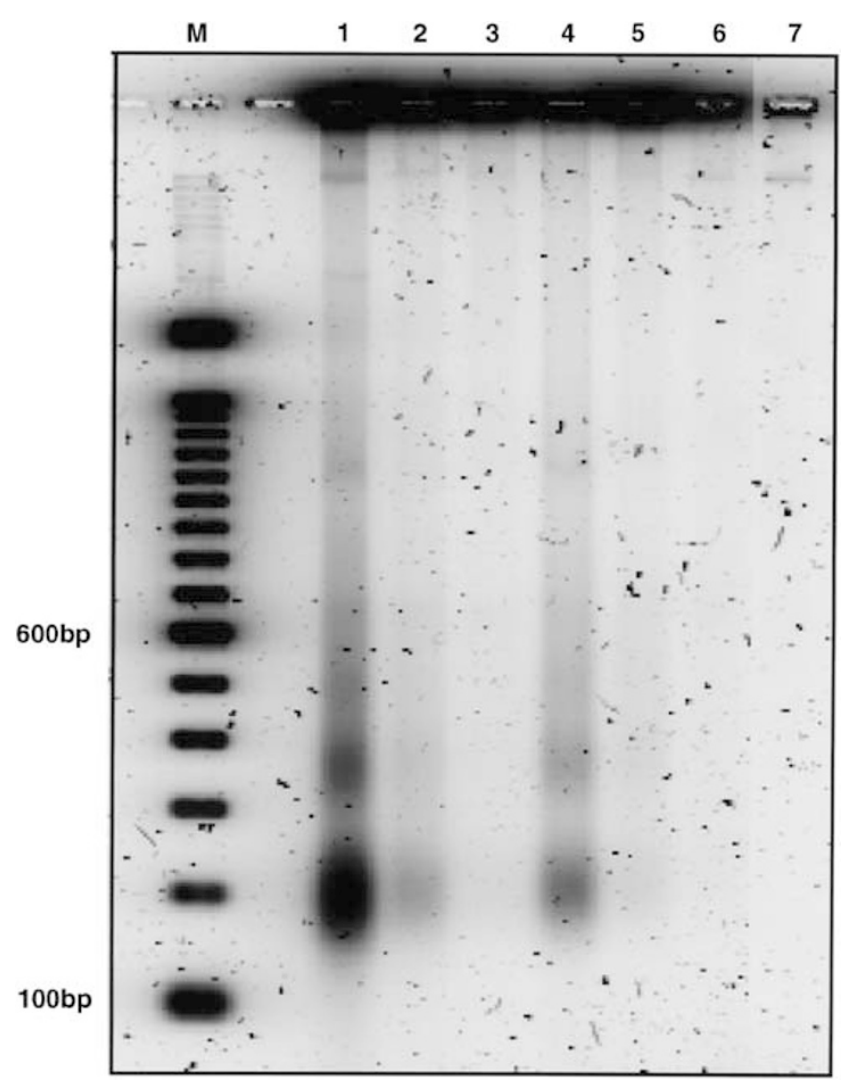

Figure 3 DNA ladder formation in rat heart administered either IL-6 or sIL-6R. Lanes 1-3 represent genomic DNA extracted from a heart exposed to $30 \mathrm{~min}$ ischemia and $3 \mathrm{~h}$ reperfusion and administered IL-6. Lanes 4-6 represent genomic DNA from a heart exposed to $30 \mathrm{~min}$ ischemia and $3 \mathrm{~h}$ reperfusion and administered sIL-6R (lanes 1 and 4: ischemic myocardium; lanes 2 and 5: border region myocardium; lanes 3 and 6: nonischemic myocardium). Genomic DNA from the ischemic and border regions (lanes 1, 2, 4, and 5) exhibited typical DNA laddering in the $200-600$ bp range; however, genomic DNA from the nonischemic region (lanes 3 and 6) exhibited preservation of high molecular weight DNA and did not exhibit DNA ladder formation typical of DNA fragmentation. Lane 7 represented genomic DNA from a sham-operated heart and exhibited only the intact high molecular weight DNA band. M represents a $100 \mathrm{bp}$ DNA ladder marker. DNA from individual hearts were used. The experiment shown is representative of three experiments.

and had therapeutic effects after systemic administration..$^{45,47,48}$

Our results demonstrated that myocardial apoptosis was inhibited by IL-6/sIL-6R complex in the border region as well as the nonischemic region. The characteristics of the border region are considered to differ from those of normal myocardium. Myocardial infarction induces regional abnormalities (asynergy) in the wall motion of the heart. The infarcted region presents with akinesis; subsequently, the border region adjacent to the ischemic region is subjected to mechanical stretching. This mechanical stretching can trigger certain signals associated with apoptosis. ${ }^{49}$ In addition, an increased workload in the border region requires an increase in oxidative metabolism for energy production; the resulting oxidative stress may activate certain signaling pathways and promote apoptosis..$^{50,51}$

Although our results provide provocative and stimulating possibilities in treatment and suggest new orientations in clinical research topics, several issues require further investigations prior to clinical application.

Apoptosis was originally termed to define essential programmed cell death and plays an important role in both development and maintenance of tissue homeostasis.. ${ }^{52-54}$ In other words, this form of altruistic cell death can be considered to be a physiologically fundamental method of ridding the body of unnecessary cells and can be considered a beneficial process in response to damage to the organism. Indeed, we have shown that the IL-6/sIL6R complex can reduce infarct size and attenuate reperfusion injury; however, it remains to be established whether rescue of these dying myocytes leads to a better clinical prognosis. Inhibiting apoptosis may possibly leave the 'rescued' myocytes electrically unstable and may lead to fatal arrhythmias. In this study, we injected all the rats with $2 \mathrm{mg} / \mathrm{kg}$ of lidocaine just after the coronary occlusion to prevent sustained VT. Then, even though we did not observe a trend towards more frequent ventricular arrhythmias in the IL-6/sIL-6R complex group, we cannot exclude the possibility that lidocaine masked the difference in arrhythmias. Further investigations are required to correctly address this problem prior to actual clinical application.

It can be argued that in these ischemia/reperfusion models, including our own, cell death occurs via two major pathways; that is, apoptosis and necrosis. While these two modes of death are mutually exclusive, they may very well coexist. Shimizu et $a l^{55}$ showed that Bcl-2 and Bcl-xL, both antiapoptotic proteins, protected mitochondria against loss of function, not only in apoptosis, but also in the process of necrosis. It has also been reported that both apoptosis and necrosis share common mediators and pathways leading to the final stages of cell death. ${ }^{56}$ To take discussion of this complicated issue further, although DNA degradation is caused by both necrosis and apoptosis, the pattern of degradation between the two processes is different. While necrosis degrades genomic DNA in a smear pattern, apoptosis degrades genomic DNA in the ladder form. In this study, the IL-6/sIL-6R complex was shown to inhibit DNA ladder formation. We thus suggest that the IL-6/sIL-6R complex contributes mainly to inhibition of apoptosis rather than to that of necrosis; however, it is difficult to differentiate between these two forms of cell death based solely on the experimental protocols used in this study. Further experiments are necessary to clarify this complicated issue.

IL-6 induces expression of the intercellular adhesion molecule-1 (ICAM-1), a mediator of neutro- 

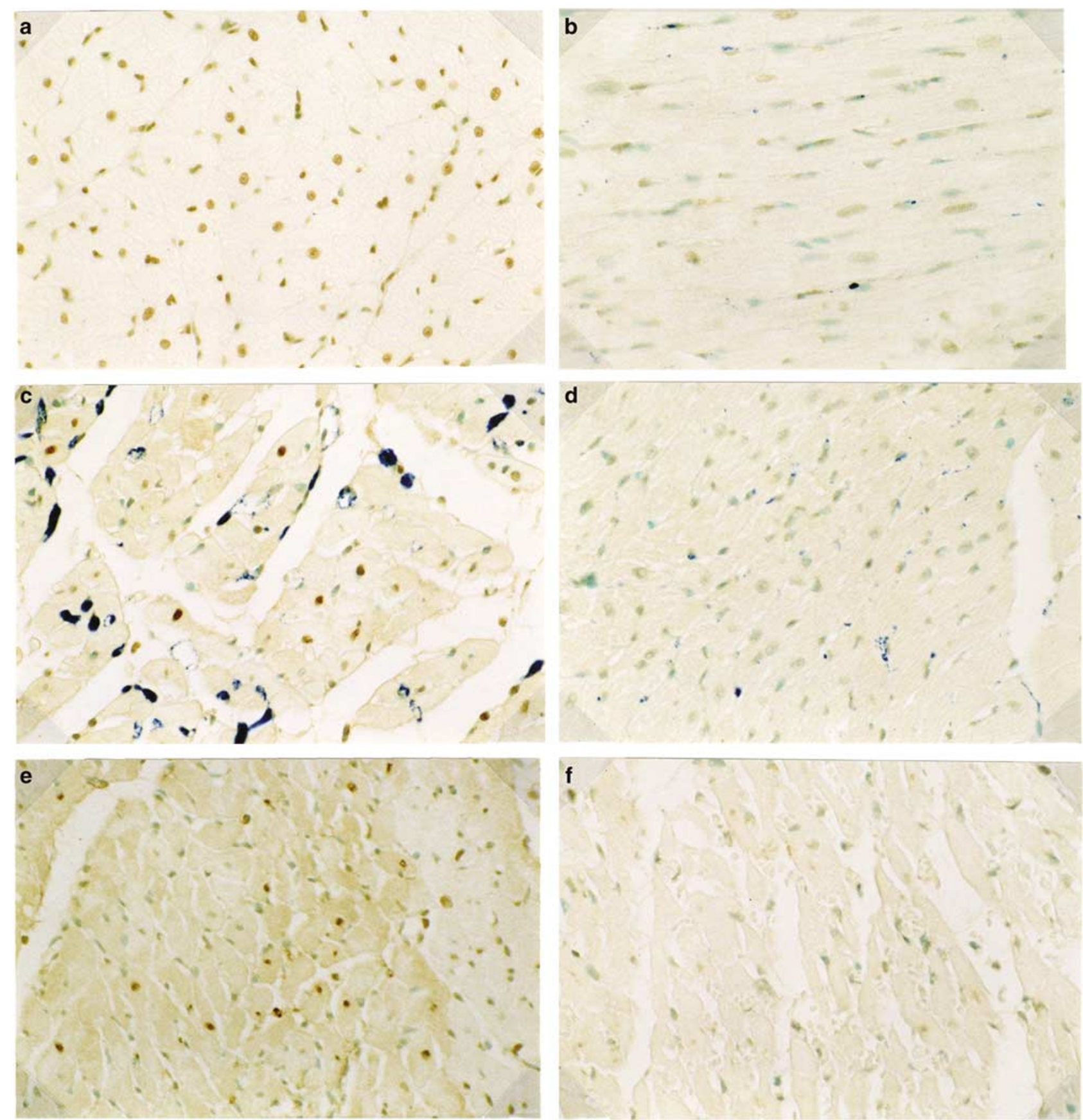

Figure 4 TUNEL staining of rat heart administered either a control vehicle or IL-6/sIL-6R complex. Tissue specimens were treated with DNA polymerase I and biotinylated dUTP, and visualized with streptavidin peroxidase and diaminobenzidine-hydrogen peroxide. Specimens were counterstained with methyl-green. Original magnification, $\times 200$. (a) Positive control: cardiac tissue specimen exposed to DNase I prior to nick end labeling. The nuclei are represented by the positive brown staining. (b) Nonischemic myocardium exposed to $30 \mathrm{~min}$ of ischemia followed by $3 \mathrm{~h}$ of reperfusion administered a control vehicle. The nuclei are stained light green by the counterstain. (c) and (d) Specimens from the border region between nonischemic and ischemic myocardium exposed to 30 min of ischemia followed by $3 \mathrm{~h}$ of reperfusion. The blue coloring indicates blood flow from phthalocyanine blue dye. (c) Represents a cardiac specimen from a rat administered a control vehicle, and (d) from a rat administered the IL-6/sIL-6R complex. In (c), numerous positive brown reaction products can be observed in the nuclei of apoptotic cells. In (d), the number of apoptotic nuclei is markedly reduced. (e) and (f) Specimens from ischemic regions exposed to $30 \mathrm{~min}$ of ischemia followed by $3 \mathrm{~h}$ of reperfusion. Ischemia was confirmed by the absence of blue dye. (e) Represents a specimen from a rat administered a control vehicle, and (f) from a rat administered the above complex. Similar to the findings in the border region, the number of apoptotic nuclei is markedly reduced following administration of the complex.

phil-induced injury, and promotes inflammation. ${ }^{57-60}$ In the myocardial ischemia-reperfusion model, Kukielka et $a l^{59}$ showed that IL-6 played an important role in the induction of ICAM-1 in the ischemic regions. Regarding the clinical study also, Ohtsuka et $a l^{61}$ clearly showed that serum levels of 

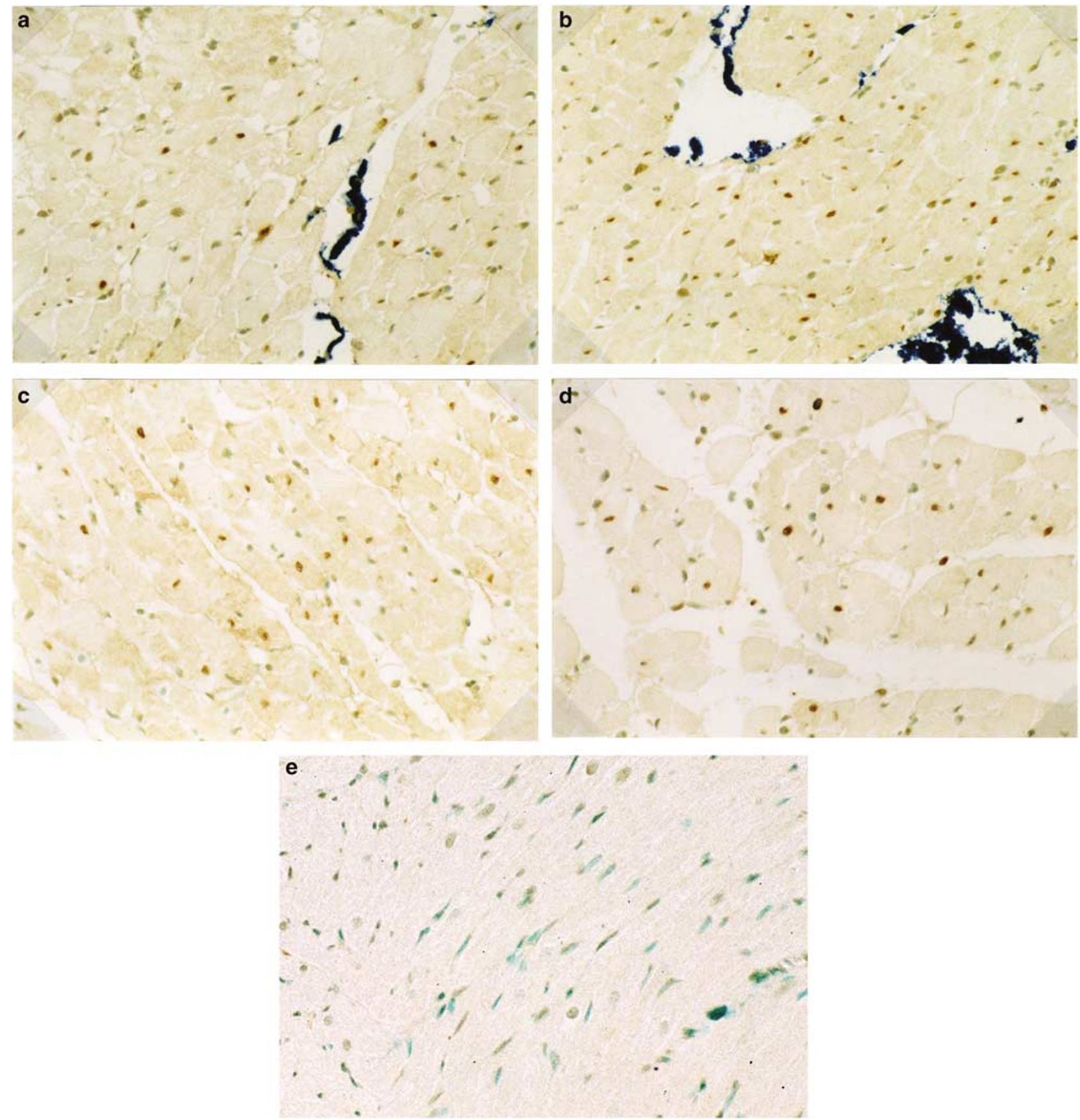

Figure 5 TUNEL staining of rat heart administered either IL-6 or sIL-6R. (a) and (b) Specimens from the border region between nonischemic and ischemic myocardium exposed to $30 \mathrm{~min}$ of ischemia followed by $3 \mathrm{~h}$ of reperfusion. The blue coloring indicates blood flow from phthalocyanine blue dye. (a) Represents a cardiac specimen from a rat administered IL-6, and (b) from a rat administered sIL6R. (c) and (d) Specimens from ischemic regions exposed to $30 \mathrm{~min}$ of ischemia followed by $3 \mathrm{~h}$ of reperfusion. Ischemia was confirmed by the absence of blue dye. (c) Represents a specimen from a rat administered IL-6, and (d) from a rat administered IL-6R. In (a)-(d), numerous TUNEL-positive nuclei can be observed. (e) Represents a specimen obtained from a sham operation. The nuclei are stained light green by the counterstain. Original magnification, $\times 200$.

IL-6 correlated well negatively with the change in the reduction of LV end-diastolic volume index 6 months after onset of myocardial infarction. They concluded that circulating IL-6 at the acute phase is a powerful independent predictor of LV remodeling after reperfused myocardial infarction. ${ }^{61}$ Therefore, we have to consider potential adverse effects of 


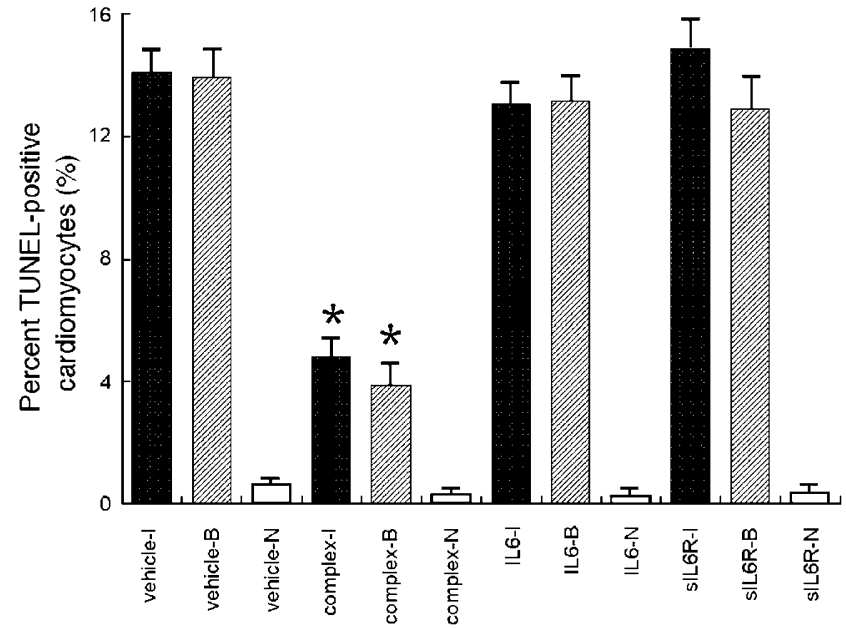

Figure 6 Bar graph representing the ratio of TUNEL-positive myocytes in rat heart specimens. The number of TUNEL-positive cardiomyocyte nuclei was divided by the total number of cardiomyocyte nuclei to determine the ratio of TUNEL-positive myocytes. In ischemic (I: solid bars) and border (B: hatched bars) regions, the ratio of TUNEL-positive myocytes in the IL-6/sIL-6R complex group was significantly smaller than that in the vehicle, the IL-6, or the sIL-6R groups. In the nonischemic (N: open bars) regions, TUNEL-positive myocytes were rarely detected in the rat hearts. Six representative microscopic fields were analyzed for each region. ${ }^{*} P<0.05$ vs vehicle, IL-6, or sIL-6R in each region. The error bar represents the s.e.m.

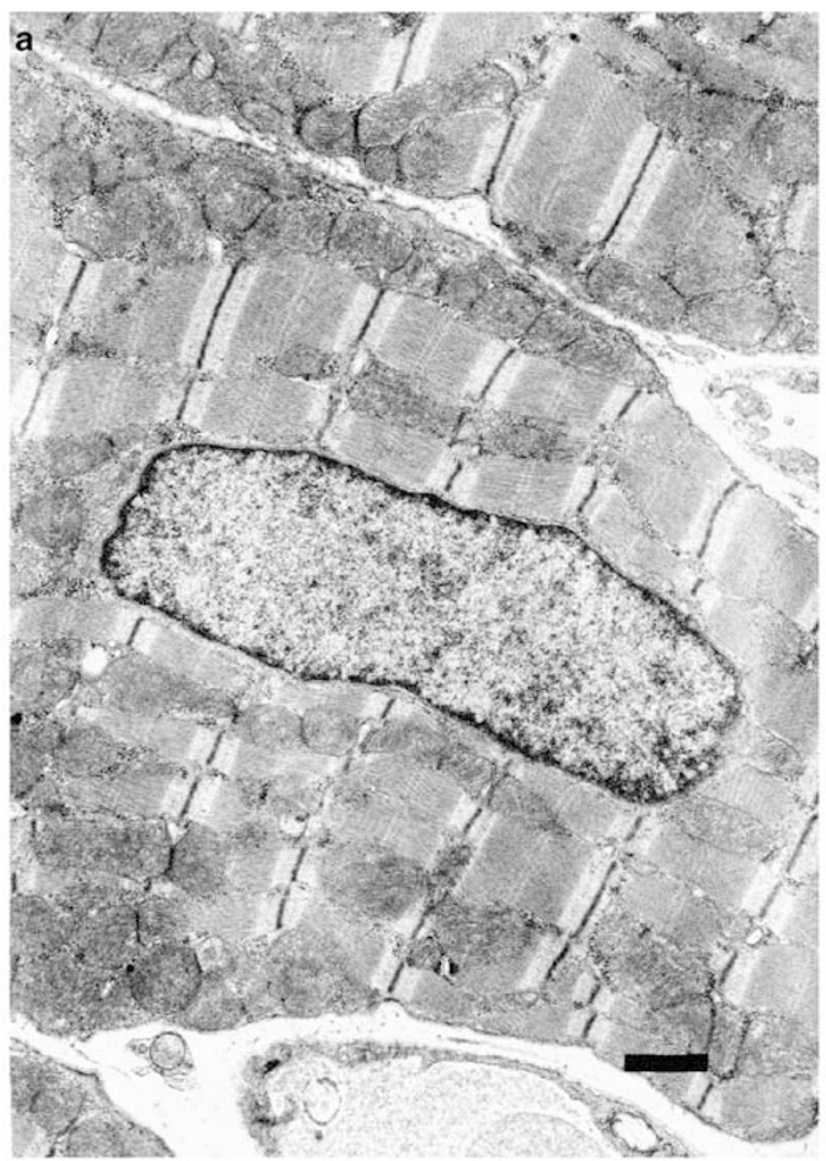

vehicle-treated, IL-6/sIL-6R complex-treated, IL-6treated, and sIL-6R-treated groups. However, we used an acute model, and it is possible that injection of the IL-6 or IL-6/sIL-6R complex is associated with upregulation of the inflammatory response during the chronic phase. Although the antiapoptotic cytoprotective effect of the complex was thought to be stronger than its proinflammatory effect in our acute model, the balance may be changed in a chronic model. More data will be needed before the

$\begin{array}{llllll} & 0 & 5 & 15 & 30 & 60 \mathrm{~min} \\ \text { gp130 } & & & \\ & & & \\ & & \\ & & \\ & & \text { IP: Anti-pTyr } \\ & \text { Blot: Anti-gp130 }\end{array}$

Figure 8 Time course of gp130 phosphorylation after the injection of IL-6/sIL-6R complex. Tissue samples obtained from left ventricle were examined at various times after injection of IL6/sIL-6R complex into LV cavity. Equal amount of proteins from left ventricle of rat hearts obtained $0,5,15,30$, and 60 min after injection of IL-6/sIL-6R complex were lysed with lysis buffer, immunoprecipitated with antiphosphotyrosine antibody, separated by $7.5 \%$ SDS-PAGE, and transferred onto a polyvinylidene difluoride (PVDF) membrane. The blot was probed with antigp130 antibody. The experiment shown is representative of three experiments.

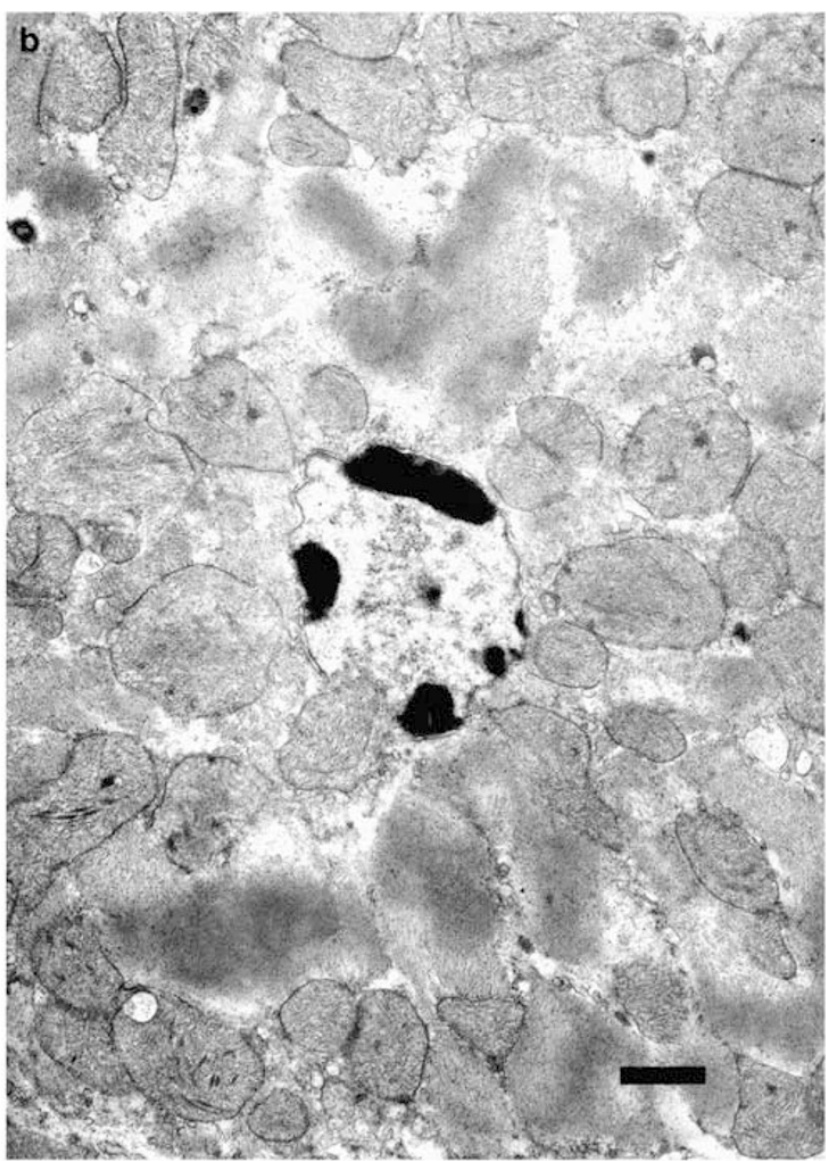

Figure 7 Electron micrographs of cardiomyocytes. (a) Cardiomyocyte specimen taken from a sham operation. (b) Cardiomyocyte specimen of the border region exposed to $30 \mathrm{~min}$ ischemia and $3 \mathrm{~h}$ reperfusion administered a control vehicle. Apoptotic myocytes present with chromatin condensation along the nuclear membrane. Bar represents $1 \mu \mathrm{m}$. 
Table 3 Left ventricular $\mathrm{d} P / \mathrm{d} t$ (positive and negative)

$L V d \mathrm{P} / \mathrm{dt}$ (positive/negative), $\mathrm{mmHg} / \mathrm{s}$

Vehicle IL-6/sIL-6R complex

$\begin{array}{lll}\text { Baseline } & +4667 \pm 422 /-2850 \pm 275 & +4620 \pm 543 /-2820 \pm 260 \\ \text { occ 30 } & +3567 \pm 340 /-2292 \pm 187 & +4650 \pm 650 /-3225 \pm 439 \\ \text { rep 30 } & +3714 \pm 264 /-2571 \pm 277 & +4940 \pm 542 /-3280 \pm 256 \\ \text { rep 180 } & +4429 \pm 468 /-3214 \pm 343 & +4130 \pm 356 /-3180 \pm 433\end{array}$

IL-6 = interleukin-6; sIL-6R = soluble interleukin-6 receptor; occ $=$ occlusion; rep = reperfusion

clinical implications of the actions of this complex become clearer.

In our models, the effects of the drugs were produced by a systemic injection, rather than a coronary injection. Hajjar et $a l^{62}$ occluded the aorta and pulmonary artery to insure that the coronary arteries were perfused for gene delivery studies in vivo. If the drugs in the present study had been delivered to the coronaries with the large vessel occlusions, the effect might have been larger than the result we obtained. It is also very important how long the drug can keep its effects. Peters et $a l^{63}$ examined how long the exogenous IL-6 or IL-6/sIL6R complex lasted. They injected mice intraperitoneally with either $40 \mu \mathrm{g}$ of IL-6 or $4 \mu \mathrm{g}$ of IL-6/sIL-6R complex per mouse and investigated the acute phase response gene expression in the livers of those mice. Their results showed that the effect of $40 \mu \mathrm{g}$ of IL-6 lasted $24 \mathrm{~h}$ and the effect of $4 \mu \mathrm{g}$ of IL-6/sIL-6R complex lasted $72 \mathrm{~h}$. The gene expression in mice received IL-6/sIL-6R complex was much stronger than that in mice received IL-6. They concluded that the IL-6/sIL-6R complex is active markedly long. ${ }^{63}$ Whether cardiomyocytes express the IL-6 receptor is controversial. Youker et $a l^{20}$ showed that IL-6 activated the IL-6 signal pathway in cardiomyocytes. In target cells expressing membrane-bound IL-6 receptors, the function of IL-6 is further augmented by the addition of sIL-6Rs. ${ }^{17,18}$ Although IL-6 alone had no effect on cardiomyocyte apoptosis in our models, IL-6 alone might have been effective if large vessel occlusions had been used. Technically, the administration of the IL-6/sIL-6R complex can be clinically implemented in humans by selectively injecting the IL-6/sIL-6R complex into the target coronary artery during primary angioplasty or intracoronary thrombolysis.

In conclusion, the present study demonstrates for the first time that the IL-6/sIL-6 receptor complex is effective in ameliorating reperfusion injury in acute myocardial infarction. This effect may be more dramatic in humans; this is because only systemic administration was possible in our experimental rat models whereas more selective administration would be possible in humans. Thus our results hint at possible novel therapies for acute myocardial infarction.

\section{Acknowledgements}

We greatly appreciate Dr Tadamitsu Kishimoto (Osaka University) for providing us with human soluble IL-6 receptor. We are also grateful to Dr Atsushi Suzuki for his criticism and discussion. In addition, we are grateful to $\mathrm{Mr}$ Naomichi Yagi, Ms Yuko Hashimoto, Mr Satoshi Kusakari and Mr Hitoshi Abe for their technical assistance.

\section{Conflict of interest}

There is no conflict of interest and financial disclosure. No financial support was received.

\section{References}

1 Tamura T, Udagawa N, Takahashi N, et al. Soluble interleukin-6 receptor triggers osteoclast formation by interleukin 6. Proc Natl Acad Sci USA 1993;90: 11924-11928.

2 Mihara M, Moriya Y, Ohsugi Y. IL-6-soluble IL-6 receptor complex inhibits the proliferation of dermal fibroblasts. Int J Immunopharmacol 1996;18:89-94.

3 Gaillard JP, Liautard J, Klein B, et al. Major role of the soluble interleukin-6/interleukin-6 receptor complex for the proliferation of interleukin-6-dependent human myeloma cell lines. Eur J Immunol 1997;27:3332-3340.

4 Kordula T, Rydel RE, Brigham EF, et al. Oncostatin M and the interleukin-6 and soluble interleukin-6 receptor complex regulate alpha1-antichymotrypsin expression in human cortical astrocytes. J Biol Chem 1998; 273:4112-4118.

5 Marz P, Herget T, Lang E, et al. Activation of gp130 by IL-6/soluble IL-6 receptor induces neuronal differentiation. Eur J Neurosci 1997;9:2765-2773.

6 Kallen KJ. The role of transsignalling via the agonistic soluble IL-6 receptor in human diseases. Biochim Biophys Acta 2002;1592:323-343.

7 Rose-John S, Heinrich PC. Soluble receptors for cytokines and growth factors: generation and biological function. Biochem J 1994;300(Part 2):281-290.

8 Jones SA, Horiuchi S, Topley N, et al. The soluble interleukin 6 receptor: mechanisms of production and implications in disease. FASEB J 2001;15:43-58.

9 Saito M, Yoshida K, Hibi M, et al. Molecular cloning of a murine IL-6 receptor-associated signal transducer, gp130, and its regulated expression in vivo. J Immunol 1992;148:4066-4071.

10 Schindler R, Mancilla J, Endres S, et al. Correlations and interactions in the production of interleukin-6 (IL6 ), IL-1, and tumor necrosis factor (TNF) in human blood mononuclear cells: IL-6 suppresses IL-1 and TNF. Blood 1990;75:40-47.

11 Tilg H, Trehu E, Atkins MB, et al. Interleukin-6 (IL-6) as an anti-inflammatory cytokine: induction of circulating IL-1 receptor antagonist and soluble tumor necrosis factor receptor p55. Blood 1994;83:113-118.

12 Heinrich PC, Behrmann I, Muller-Newen G, et al. Interleukin-6-type cytokine signalling through the gp130/Jak/STAT pathway. Biochem J 1998;334(Part 2): 297-314. 
13 Fukada T, Hibi M, Yamanaka Y, et al. Two signals are necessary for cell proliferation induced by a cytokine receptor gp130: involvement of STAT3 in anti-apoptosis. Immunity 1996;5:449-460.

14 Lichtenstein A, Tu Y, Fady C, et al. Interleukin-6 inhibits apoptosis of malignant plasma cells. Cell Immunol 1995;162:248-255.

15 Hitzler JK, Martinez-Valdez H, Bergsagel DB, et al. Role of interleukin-6 in the proliferation of human multiple myeloma cell lines OCI-My 1 to 7 established from patients with advanced stage of the disease. Blood 1991;78:1996-2004.

16 Kawano M, Hirano T, Matsuda T, et al. Autocrine generation and requirement of BSF-2/IL-6 for human multiple myelomas. Nature 1988;332:83-85.

17 Honda M, Yamamoto S, Cheng M, et al. Human soluble IL-6 receptor: its detection and enhanced release by HIV infection. J Immunol 1992;148:2175-2180.

18 Taga T, Hibi M, Hirata Y, et al. Interleukin-6 triggers the association of its receptor with a possible signal transducer, gp130. Cell 1989;58:573-581.

19 Kunisada K, Tone E, Fujio Y, et al. Activation of gp130 transduces hypertrophic signals via STAT3 in cardiac myocytes. Circulation 1998;98:346-352.

20 Youker K, Smith CW, Anderson DC, et al. Neutrophil adherence to isolated adult cardiac myocytes. Induction by cardiac lymph collected during ischemia and reperfusion. J Clin Invest 1992;89:602-609.

21 Chandrasekar B, Mitchell DH, Colston JT, et al. Regulation of CCAAT/Enhancer binding protein, interleukin-6, interleukin-6 receptor, and gp130 expression during myocardial ischemia/reperfusion. Circulation 1999;99:427-433.

22 Fliss H, Gattinger D. Apoptosis in ischemic and reperfused rat myocardium. Circ Res 1996;79: 949-956.

23 Ryan TJ, Antman EM, Brooks NH, et al. 1999 update: ACC/AHA Guidelines for the Management of Patients With Acute Myocardial Infarction: Executive Summary and Recommendations: A report of the American College of Cardiology/American Heart Association Task Force on Practice Guidelines (Committee on Management of Acute Myocardial Infarction). Circulation 1999;100:1016-1030.

24 Braunwald E, Kloner RA. Myocardial reperfusion: a double-edged sword? J Clin Invest 1985;76:1713-1719.

25 Kloner RA. Does reperfusion injury exist in humans? J Am Coll Cardiol 1993;21:537-545.

26 Gottlieb RA, Burleson KO, Kloner RA, et al. Reperfusion injury induces apoptosis in rabbit cardiomyocytes. J Clin Invest 1994;94:1621-1628.

27 Saraste A, Pulkki K, Kallajoki M, et al. Apoptosis in human acute myocardial infarction. Circulation 1997; 95:320-323.

28 Dzau VJ. Predicting the future of human gene therapy for cardiovascular diseases: what will the management of coronary artery disease be like in 2005 and 2010? Am J Cardiol 2003;92:32N-35N.

29 Zhu B, Sun Y, Sievers RE, et al. Comparative effects of pretreatment with captopril and losartan on cardiovascular protection in a rat model of ischemiareperfusion. J Am Coll Cardiol 2000;35:787-795.

30 Novick D, Engelmann H, Wallach D, et al. Soluble cytokine receptors are present in normal human urine. J Exp Med 1989;170:1409-1414.

31 Muller-Newen G, Kuster A, Hemmann U, et al. Soluble IL-6 receptor potentiates the antagonistic activity of soluble gp130 on IL-6 responses. J Immunol 1998;161: 6347-6355.

32 Oh JW, Revel M, Chebath J. A soluble interleukin 6 receptor isolated from conditioned medium of human breast cancer cells is encoded by a differentially spliced mRNA. Cytokine 1996;8:401-409.

33 Peters M, Jacobs S, Ehlers M, et al. The function of the soluble interleukin 6 (IL-6) receptor in vivo: sensitization of human soluble IL-6 receptor transgenic mice towards IL-6 and prolongation of the plasma half-life of IL-6. J Exp Med 1996;183:1399-1406.

34 Matsushita K, Umezawa A, Iwanaga S, et al. The EAT/ mcl-1 gene, an inhibitor of apoptosis, is up-regulated in the early stage of acute myocardial infarction. Biochim Biophys Acta 1999;1472:471-478.

35 El Mouedden M, Laurent G, Mingeot-Leclercq MP, et al. Gentamicin-induced apoptosis in renal cell lines and embryonic rat fibroblasts. Toxicol Sci 2000;56: 229-239.

36 Carabello BA. Evolution of the study of left ventricular function: everything old is new again. Circulation 2002;105:2701-2703.

37 Gleason WL, Braunwald E. Studies on the first derivative of the ventricular pressure pulse in man. J Clin Invest 1962;41:80-91.

38 Wallace AG, Skinner Jr NS, Mitchell JH. Hemodynamic determinants of the maximal rate of rise of left ventricular pressure. Am J Physiol 1963;205:30-36.

39 Chen C, Ma L, Linfert DR, et al. Myocardial cell death and apoptosis in hibernating myocardium. J Am Coll Cardiol 1997;30:1407-1412.

40 Latif N, Khan MA, Birks E, et al. Upregulation of the Bcl-2 family of proteins in end stage heart failure. J Am Coll Cardiol 2000;35:1769-1777.

41 Graeve L, Korolenko TA, Hemmann U, et al. A complex of the soluble interleukin-6 receptor and interleukin-6 is internalized via the signal transducer gp130. FEBS Lett 1996;399:131-134.

42 Horsten U, Muller-Newen G, Gerhartz C, et al. Molecular modeling-guided mutagenesis of the extracellular part of gp130 leads to the identification of contact sites in the interleukin-6 (IL-6). IL-6 receptor.gp130 complex. J Biol Chem 1997;272:23748-23757.

43 Murakami M, Hibi M, Nakagawa N, et al. IL-6-induced homodimerization of gp130 and associated activation of a tyrosine kinase. Science 1993;260:1808-1810.

44 Narazaki M, Witthuhn BA, Yoshida K, et al. Activation of JAK2 kinase mediated by the interleukin 6 signal transducer gp130. Proc Natl Acad Sci USA 1994;91: 2285-2289.

45 Ikeda K, Kinoshita M, Tagaya N, et al. Coadministration of interleukin-6 (IL-6) and soluble IL-6 receptor delays progression of wobbler mouse motor neuron disease. Brain Res 1996;726:91-97.

46 Hirota H, Yoshida K, Kishimoto T, et al. Continuous activation of gp130, a signal-transducing receptor component for interleukin 6-related cytokines, causes myocardial hypertrophy in mice. Proc Natl Acad Sci USA 1995;92:4862-4866.

47 Ikeda K, Iwasaki Y, Tagaya N, et al. Neuroprotective effect of cholinergic differentiation factor/leukemia inhibitory factor on wobbler murine motor neuron disease. Muscle Nerve 1995;18:1344-1347.

48 Mitsumoto H, Ikeda K, Holmlund T, et al. The effects of ciliary neurotrophic factor on motor dysfunction in wobbler mouse motor neuron disease. Ann Neurol 1994;36:142-148. 
49 Leri A, Claudio PP, Li Q, et al. Stretch-mediated release of angiotensin II induces myocyte apoptosis by activating p53 that enhances the local renin-angiotensin system and decreases the Bcl-2-to-Bax protein ratio in the cell. J Clin Invest 1998;101:1326-1342.

50 Aikawa R, Komuro I, Yamazaki T, et al. Oxidative stress activates extracellular signal-regulated kinases through Src and Ras in cultured cardiac myocytes of neonatal rats. J Clin Invest 1997;100:18131821.

51 Slater AF, Stefan C, Nobel I, et al. Signalling mechanisms and oxidative stress in apoptosis. Toxicol Lett 1995;82-83:149-153.

52 Gerschenson LE, Rotello RJ. Apoptosis: a different type of cell death. FASEB J 1992;6:2450-2455.

53 Korsmeyer SJ. Regulators of cell death. Trends Genet 1995;11:101-105.

54 Matsushita K, Okita H, Suzuki A, et al. Islet cell hyperplasia in transgenic mice overexpressing EAT/ mcl-1, a bcl-2 related gene. Mol Cell Endocrinol 2003; 203:105-116.

55 Shimizu S, Eguchi Y, Kamiike W, et al. Bcl-2 blocks loss of mitochondrial membrane potential while ICE inhibitors act at a different step during inhibition of death induced by respiratory chain inhibitors. Oncogene 1996;13:21-29.

56 Shimizu S, Eguchi Y, Kamiike W, et al. Retardation of chemical hypoxia-induced necrotic cell death by Bcl-2 and ICE inhibitors: possible involvement of common mediators in apoptotic and necrotic signal transductions. Oncogene 1996;12:2045-2050.

57 Deten A, Volz HC, Briest W, et al. Cardiac cytokine expression is upregulated in the acute phase after myocardial infarction. Experimental studies in rats. Cardiovasc Res 2002;55:329-340.

58 Frangogiannis NG, Youker KA, Rossen RD, et al. Cytokines and the microcirculation in ischemia and reperfusion. J Mol Cell Cardiol 1998;30:2567-2576.

59 Kukielka GL, Smith CW, Manning AM, et al. Induction of interleukin-6 synthesis in the myocardium. Potential role in postreperfusion inflammatory injury. Circulation 1995;92:1866-1875.

60 Sawa Y, Ichikawa H, Kagisaki K, et al. Interleukin-6 derived from hypoxic myocytes promotes neutrophilmediated reperfusion injury in myocardium. J Thorac Cardiovasc Surg 1998;116:511-517.

61 Ohtsuka T, Hamada M, Inoue K, et al. Relation of circulating interleukin-6 to left ventricular remodeling in patients with reperfused anterior myocardial infarction. Clin Cardiol 2004;27:417-420.

62 Hajjar RJ, Schmidt U, Matsui T, et al. Modulation of ventricular function through gene transfer in vivo. Proc Natl Acad Sci USA 1998;95:5251-5256.

63 Peters M, Blinn G, Solem F, et al. In vivo and in vitro activities of the gp130-stimulating designer cytokine Hyper-IL-6. J Immunol 1998;161:3575-3581. 